\title{
Impact of retro-reflective materials as urban coating: a theoretical study through simulations
}

\author{
Mattia Manni ${ }^{1,2}$, Gabriele Lobaccaro ${ }^{3}$, Francesco Goia ${ }^{3}$, Andrea Nicolini ${ }^{1,2}$ \\ ${ }^{1}$ Interuniversity Research Center on Pollution and Environment "Mauro Felli”, Perugia, Italy \\ ${ }^{2}$ Department of Engineering, University of Perugia, Perugia, Italy \\ ${ }^{3}$ Department of Architecture and Technology, Faculty of Architecture and Design, Norwegian \\ University of Science and Technology NTNU, Trondheim, Norway
}

\begin{abstract}
The use of retro-reflective materials has been recently proposed as a strategy to mitigate the urban overwarming by increasing the solar irradiation reflected out of the urban environment. The hereby study focuses on the definition of a methodology to estimate the impact of retro-reflective coatings through a comparison with other surface treatments such as traditional and high-reflective materials. The case study is an urban canyon located in Milan (Italy). Firstly, the impact given by the geometry and the canyon's orientation was investigated. Secondly, traditional, diffuse high-reflective and retro-reflective materials were applied to the façade and to the street. The outcomes demonstrated how the retro-reflective layer could perform better than the high-reflective when applied to the street in wide canyons, increasing by four times the solar irradiation reflected towards the sky dome. Conversely, the retro-reflective façade turns out to be more performant in narrow urban canyon models.
\end{abstract}

\section{Introduction}

Urban densification can be seen as one strategy to achieve sustainable objectives from an economic, social and environmental point of view (Lima, Scalco and Lamberts, 2019). However, densification also presents some drawbacks when it comes to energy use for building climatization. Both cooling and heating energy use are demonstrated to be influenced by the urban context because of mutual solar inter-building reflections, and by the so-called urban heat island (UHI) effect (Hassid et al., 2000; Santamouris, Paraponiaris and Mihalakakou, 2007; Santamouris et al., 2015; Allegrini, Dorer and Carmeliet, 2012; Santamouris, 2014; Xu et al., 2018). Several studies have revealed that the energy use in standing-alone buildings is lower than the amount calculated for the same building if included in a built context (Hassid et al., 2000; Santamouris, 2014; Santamouris et al., 2015). It was demonstrated that the average increase in cooling demand is around $23 \%$, whereas the corresponding average reduction of heating demand is around $19 \%$. In total, the average energy demand of building appears to increase by more than $10 \%$ by including UHI-related thermal loads (Santamouris et al., 2015). Other related consequences to the urban overwarming are represented by the reduction of natural ventilation, as well as the worsening of the air quality (lower pollutant dispersion) and people's health (Stathopoulou et al., 2008; Santamouris and Kolokotsa, 2015).
Cool materials have been recently proposed (i.e. highreflective façades, cool paving, etc.) to lower the fraction absorbed by buildings and reduce UHI effects (e.g. increment of outdoor temperature, high energy demand for cooling), although they increase the amount of solar irradiation reflected within the canyon boundaries. On the one hand, evidence from different researches proved that outdoor air temperature values can be lowered by around $5^{\circ} \mathrm{C}$ in urbanized areas by applying high-albedo materials. On the other hand, these surface treatments contribute to increasing the number of solar inter-building reflections (Han, Taylor and Pisello, 2015) and the amount of solar irradiance that is trapped at the bottom of the urban canyon (UC).

In this scenario, retro-reflective (RR) materials had been introduced as a subgroup of high-reflective (HR) layers (Rossi et al., 2014), and proposed as a potential solution to lower the UHI effect while mitigating mutual shortwave radiative exchanges among buildings. RR materials are able (i) to decrease the mutual inter-building solar reflections, (ii) to reduce the solar energy loads in the UHI boundary, and (iii) to reflect incident solar irradiation back towards the sky dome.

This paper presents an original investigation to assess the potentials of RR materials. It is structured in a background section about the state-of-the-art of RR materials and the definition of research questions and goals. The methodology section describes the workflow developed and used for the analyses, the case study, and the involved parameters. In results and discussion sections the outcomes are presented and commented; finally, a conclusion section summarizes the main findings of the study.

\section{Background}

The application of RR layers in the building sector has been only recently explored. In their studies, Nilsen and $\mathrm{Lu}$ (Nilsen and Lu, 2004) firstly introduced the use of RR coatings in buildings as a valid and efficient alternative to the traditional materials. In the review article carried out by J. Yuan (Yuan, Emura and Farnham, 2016), RR materials were compared to the HR ones discussing the advantages guaranteed by their application to urban elements (i.e. building's façade, street ground). Nevertheless, the lack of performance standards represents the main barrier to the application of RR materials as urban coatings. During the last decade, several research activities (Sakai, Emura and Igawa, 
2008; Rossi et al., 2014; Akbari and Touchaei, 2014; Rossi et al., 2015; Qin et al., 2016) have focused on the characterization of RR materials, ranging from the definition of an assessing protocol to the evaluation of their specific RR properties. Commercial films (prismarray structured), capsule-lens, and bead-embedded layers were analyzed and compared after they have been tested in miniature models of UCs or districts to demonstrate their effectiveness in mitigating UHI (Sakai et al., 2008; Rossi et al., 2014). The measurement facility employed in (Rossi et al., 2015) to test the efficiency of RR materials was equipped with 19 photodiodes (with a $10^{\circ}$ wide step, from $0^{\circ}$ to $180^{\circ}$ ), which estimate the reflected fractions in different directions. The outcomes from different samples demonstrated how a RR behaviour can be usually observed when the solar irradiation hits the material mainly perpendicularly, while an HR behaviour is shown in the case of mostly parallel sunrays' direction.

Despite the proven advantages of the different RR technologies, there are still some aspects, which need to be addressed to fully enable the potentialities of these systems. Indeed, the RR materials could present some side effects such as (i) the increment of heating energy requirements in winter, since less solar irradiation is absorbed by the façades; and (ii) the higher lighting pollution level due to the reduction of urban surfaces able to absorb the city lights. To overcome these issues, two materials, which could be classified as selective RR materials, have been proposed by Sakai and Iyota (Sakai and Iyota, 2017), while a new inverse approach has been recently proposed (Manni et al., 2018) to identify optimal selective angular properties of RR surfaces (both horizontal and vertical).

In this scenario, the study presented in this paper aims at giving an original contribution to the evaluation process of RR materials by proposing a methodology to preliminary assess their mitigation potential in different UC environments.

\section{Methodology}

The methodology is based on a cluster of solar analyses which separately assess the contributions from direct and diffuse solar irradiation. It is applied to carry out a comparison among traditional, HR, and RR materials. Because of the numerical modeling approach, based on Radiance, this paper also investigates the suitability of ray tracing simulation to predict the potentials of the application of RR materials to increase the amount of solar irradiation reflected beyond the canyon. Some representative UC configurations are considered, where RR coatings are applied to street and building's façade.

\section{Workflow and parameters}

As reported in Figure 1, the research is structured in two stages. Stage 1 aims at defining the UC models characterized by the highest and the lowest amounts of solar irradiation reflected towards the sky dome in order to provide two geometry configurations where different material patterns can be assessed in Stage 2. The main input parameters are the orientation of the UC, the aspect height-to-width ratio $(\mathrm{H} / \mathrm{W})$, and the geographical and climate information. The output considered during the selection process of the UC geometry configurations is the amount of solar irradiation reflected beyond the canyon by all the surfaces ( $\left.\operatorname{Irr}_{\text {out }}\right)$.

The solar analyses for Milan latitude were carried out by changing the UC orientation (north-south, east-west, and northwest-southeast) and the $\mathrm{H} / \mathrm{W}$ (from 0.5 to 1.0 , and to 2.0) to explore low, medium, and high urban density patterns. In total, 9 different geometry configurations were investigated (Figure 2). The length of the building fabrics is set to avoid any uncontrolled boundary effects

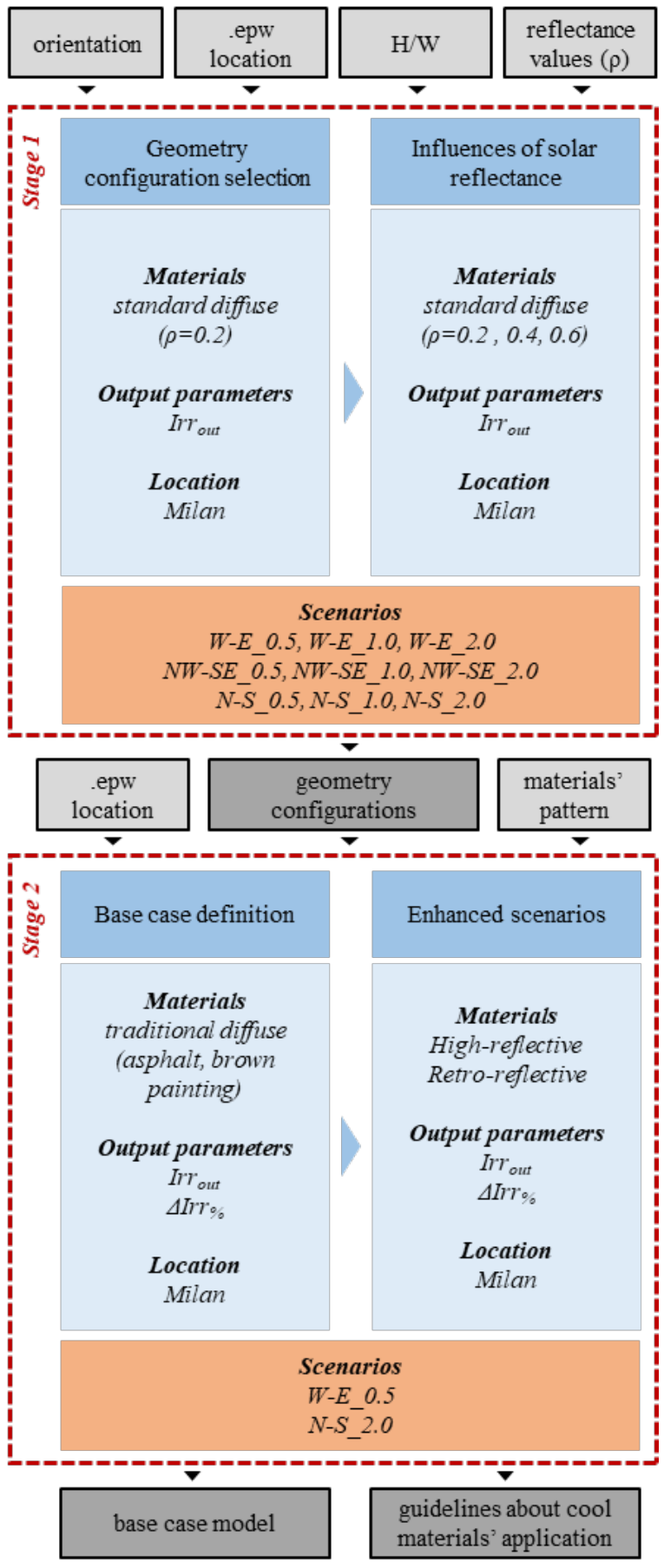

Figure 1: Overview of the workflow. The main inputs and outputs are reported along with the investigated scenarios for each stage. 
in the middle of the canyon during the calculation. This is obtained by multiplying the canyon's width by six. Therefore, the building blocks vary through the study according to the $\mathrm{H} / \mathrm{W}$ aspect ratio. For an $\mathrm{H} / \mathrm{W}$ equal to 1.0 , the building blocks are $6 \mathrm{~m}$ of height $(\mathrm{H}) \times 6 \mathrm{~m}$ of width (W) $x 36 \mathrm{~m}$ of length (L). In case of $\mathrm{H} / \mathrm{W}$ equal to 2.0 , the building fabrics' height is doubled up to $12 \mathrm{~m}$, whereas in the last geometry configuration $-\mathrm{H} / \mathrm{W}$ of 0.5 - the streets' width is increased from $6 \mathrm{~m}$ to $12 \mathrm{~m}$ while the height of the building is kept constant up to $6 \mathrm{~m}$ (Figure 3).

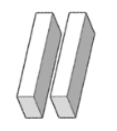

N-S_2.0
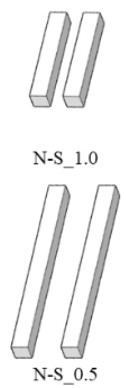

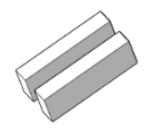

NW-SE_2.0

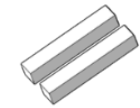

NW-SE_1.0

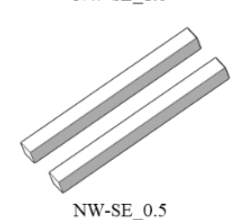

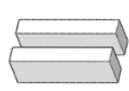

W-E_2.0

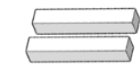

W-E_1.0

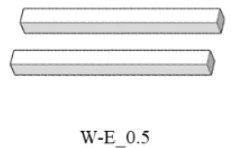

Figure 2: Overview of the 9 geometry configurations of UC obtained by varying the canyon's orientation and the $H / W$ aspect ratio.

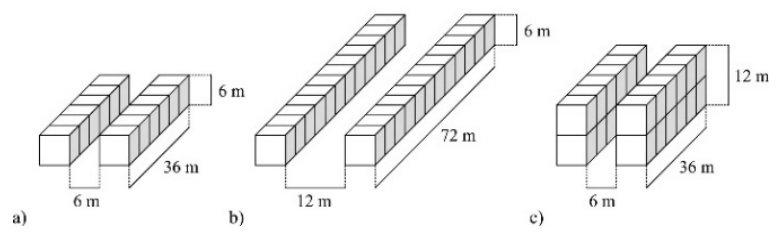

Figure 3: From the left: UC geometry configurations and dimensions in case of $H / W$ equal to (a) 1.0, (b) 0.5 , and (c) 2.0.

In the second part of Stage 1, the influences of the solar reflectance parameter $(\rho)$ on the outcomes carried out from the first cluster of analyses were assessed by varying the homogenous $\rho$ value set for the canyon's surfaces from 0.2 to 0.4 , and to 0.6 . These analyses were conducted for the two extreme scenarios and an intermediate one.

The two case studies selected at the end of Stage 1 were used in Stage 2 to investigate three surface treatments (traditional diffuse, diffuse HR, and RR materials) to be applied to the street and to the façade. The scenario with traditional diffuse materials (named as 'base case') was compared to the ones exploiting HR and RR materials (named as 'cool scenarios'). The output parameter evaluated in this part of the study is the percent variation ( $\Delta \operatorname{Irr}_{\%}$ ) between the $\operatorname{Irr}_{\text {out }}$ estimated for the cool scenario and the one calculated for the base case.

\section{Material properties and simulated scenarios}

A generic Lambertian diffuse coating with a solar reflectance value of 0.2 was used in the selection process of the UC models in Stage 1. Then, the $\rho$ value was increased from 0.2 to 0.4 , and to 0.6 to assess the dependency of the results from the chosen solar reflectance number.

The base case defined during Stage 2 shows traditional diffuse materials from standard Radiance library applied to the street (asphalt, $\rho=0.2$ ) and to the building's façades (brown painting, $\rho=0.35$ ).

As far as the cool treatments are concerned, the wording 'high-reflective materials' identifies a cluster of materials characterized by a solar reflectance higher than 0.90 , while the wording 'retro-reflective materials' is referred to a group of coatings able to totally reflect back towards the skydome the solar irradiation impinging on the surface.

Two scenarios were assessed for HR and RR materials depending on their field of application (street or façade). Therefore, the investigated materials patterns are the ones reported in Table 1. In cool scenarios, conventional materials are always applied to those surfaces where HR or RR treatments are not exploited (i.e. to street surface in HR-F scenario).

Table 1: Overview of the material patterns investigated during Stage 2.

\begin{tabular}{|c|c|c|c|}
\hline \multirow{2}{*}{ Scenario } & \multicolumn{3}{|c|}{ Applied Material } \\
\cline { 2 - 4 } & $\begin{array}{c}\text { Façade facing } \\
\text { south (or east) }\end{array}$ & Street & $\begin{array}{c}\text { Façade facing } \\
\text { north (or west) }\end{array}$ \\
\hline base case & brown painting & asphalt & brown painting \\
\hline HR-P & brown painting & HR & brown painting \\
\hline HR-F & HR & asphalt & brown painting \\
\hline RR-P & brown painting & RR & brown painting \\
\hline RR-F & RR & asphalt & brown painting \\
\hline
\end{tabular}

\section{Simulation tool and data processing}

The UC investigated in this study was parametrically modelled in Grasshopper environment and it was visualized in Rhinoceros to generate different geometry configurations by modifying the algorithm's input values (i.e. $\mathrm{H} / \mathrm{W}$ ratio, orientation).

The Diva for Rhino plug-in, based on Radiance engine, was chosen to conduct solar analyses using the .epw weather data climate of Milan (Italy). A grid of test points facing the street was generated by offsetting the ground surface by a distance equal to the building's height. A cells' size of one meter by one meter was also considered (Figure 4).

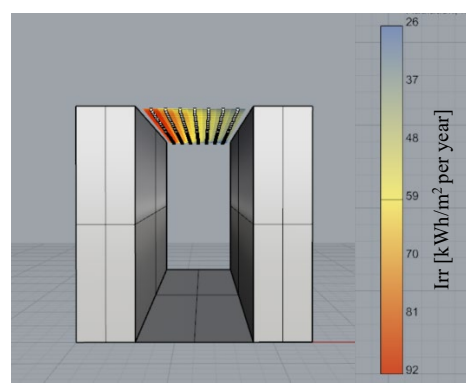

Figure 4: Grid of test points set for the solar analyses. 
Table 2: Set of 'rtrace' parameters employed for conducting solar radiation analyses with Diva-forRhino.

\begin{tabular}{|c|c|c|c|c|}
\hline $\begin{array}{c}\text { Ambient } \\
\text { bounces }\end{array}$ & $\begin{array}{c}\text { Ambient } \\
\text { divisions }\end{array}$ & $\begin{array}{c}\text { Ambient } \\
\text { super } \\
\text { samples }\end{array}$ & $\begin{array}{c}\text { Ambient } \\
\text { resolution }\end{array}$ & $\begin{array}{c}\text { Ambient } \\
\text { accuracy }\end{array}$ \\
\hline $0 / 1 / 5$ & 1,000 & 20 & 300 & 0.1 \\
\hline
\end{tabular}

The Radiance simulation parameters were set as shown in Table 2. The outputs are referred to the solar irradiation incident on the test points throughout the year, which has been evaluated both yearly and seasonally. The $\operatorname{Irr}_{\text {out }}$ is estimated as the specific solar irradiation per square meter impinging the one-meter-wide strip surface located at the middle of the canyon (it permits to avoid boundary effects). The extension of the strip ranges from $6 \mathrm{~m}^{2}(\mathrm{H} / \mathrm{W}$ of 1.0 and 2.0$)$ to $12 \mathrm{~m}^{2}(\mathrm{H} / \mathrm{W}$ of 0.5$)$.

The ambient bounces (ab) value, that counts the number of the solar reflections before the sunray hits the analyzed surface, was set equal to 5 to estimate global solar irradiance composed by diffuse, direct and up to fifthreflection contribution ( $\operatorname{Irr}_{\text {tot }}$ ). This last setting guarantees the ideal compromise between computational time and accuracy of the results when it comes to multiple reflections (Pesenti, Masera and Fiorito, 2018). The values of 0 and 1 for ab were used to calculate the solar incident irradiation component due to direct $\left(\operatorname{Irr}_{\text {dir,inc }}\right)$ and diffuse solar irradiation ( $\left.\operatorname{Irr}_{\text {dif,inc }}\right)$. In particular, a weather file customized in Elements environment has been generated with null values for the direct sunlight. It has been used in the assessment of the diffuse fraction.

The analyses were conducted with an hourly time-step throughout the whole year. The yearly duration was organized according to the four seasons: spring (March, April, May), summer (June, July, August), fall, (September, October, November) and winter (December, January, February).

Custom Radiance materials properties were set considering the parameters of colour (RGB values), specularity (fraction of incident light that is reflected; varying from 0.0 for a perfectly diffusive surface to 1.0 for a perfect mirror), and roughness (surface irregularities quantified by the deviation from its ideal direction of the normal vector of a surface; the value varies from 0.0 , which corresponds to a perfectly smooth surface, to 1.0 that corresponds to a perfectly irregular surface).

Since models of RR materials are not available, the proposed approach is based on the manipulation of weather data file and materials' properties. Three independent simulations were carried out to define the three retro-reflected contributions - direct (Figure 5 a) and diffuse (Figure $5 \mathrm{~b}$ ) solar irradiation retro-reflected from the RR surface, and global solar irradiation reflected out of the UC from the non-RR surfaces (Figure $5 \mathrm{c}$ ) - and arithmetically add them. In particular, a material able to completely absorb the solar radiation impinging on the surface (null $\rho$ value) was used instead of the RR materials to calculate the solar irradiation reflected beyond the UC by non-RR surfaces.

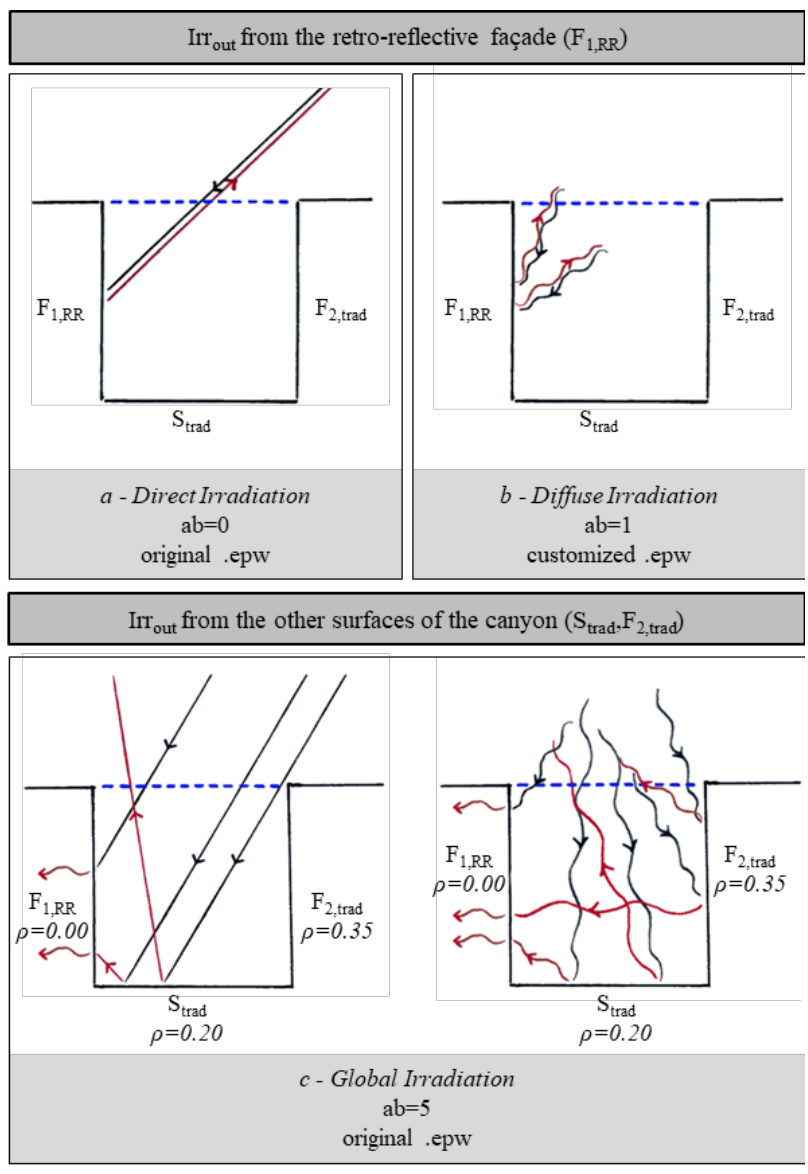

Figure 5: Schematic representation of the approach followed to estimate the three components of $\operatorname{Irr}_{\text {out }}(a, b$, and c) when $R R$ are applied to the façade $\left(F_{1, R R}\right)$.

This simplification leads to underestimating the $\operatorname{Irr}_{\text {out }}$ since a minimum fraction of the solar irradiance absorbed by the surface with null $\rho$ value would be actually retroreflected towards the street or the façade, and then eventually further reflected beyond the canyon.

\section{Results}

\section{Definition of the $\mathrm{UC}$ configurations}

The estimated solar irradiation reflected by the UC underline how the orientation input parameter provides a negligible variation (lower than 3\%) in canyon's configurations with the same H/W (Figure 6). Conversely, the $\mathrm{H} / \mathrm{W}$ influences the $\operatorname{Irr}_{\text {out }}$ : its least, $85 \mathrm{kWh} / \mathrm{m}^{2}$, is shown in the narrowest geometry configuration $(\mathrm{H} / \mathrm{W}$ equal to 2.0), while the maximum, $160 \mathrm{kWh} / \mathrm{m}^{2}$, corresponds to the widest $(\mathrm{H} / \mathrm{W}$ equal to 0.5$)$. These two extremes were chosen as the $\mathrm{H} / \mathrm{W}$ values proper of the best and the worst UC configurations.

When it comes to the orientation, the west-east was coupled to the $0.5 \mathrm{H} / \mathrm{W}$ value (the resulting model was named as 'W-E_0.5') and the north-south to the $2.0 \mathrm{H} / \mathrm{W}$ (the resulting model was named as ' $\mathrm{N}-\mathrm{S} \_2.0$ '). They were considered as the most and the least advantageous orientations, respectively, since they are characterized by the greatest and the lowest difference in terms of collected solar irradiation among the façades (Vallati, Mauri and Colucci, 2018). 


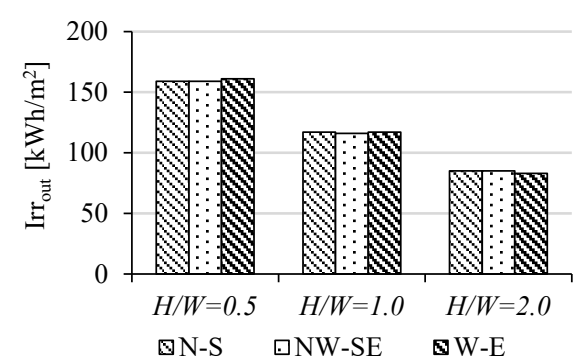

Figure 6: Comparison of Irr out values estimated for each geometry configuration considering a homogeneous solar reflectance of 0.2 for the whole UC.

In the second part of Stage 1, the solar reflectance parameter was investigated. The W-E_0.5 and the NS 2.0 models were considered as case studies along with an intermediate one (named as 'NW-SE 1.0') that is oriented northwest-southeast and whose $\mathrm{H} / \mathrm{W}$ is equal to 1.0. Increasing the $\rho$ value, the $\operatorname{Irr}_{\text {out }}$ raises similarly in all the models. In particular, varying the solar reflectance from 0.2 to 0.4 doubles the estimated $\operatorname{Irr}_{\text {out }}$, while the variation is lower when incrementing from 0.4 to 0.6 (Figure 7).

The chosen homogenous solar reflectance $(\rho=0.2)$ does not influence the relationship among the different geometry configurations in terms of solar irradiation leaving the UC (i.e. varying the $\rho$ value, the $\operatorname{Irr}_{\text {out }}$ estimated for the N-S_2.0 is always lower than the amount calculated for the W-E_0.5).

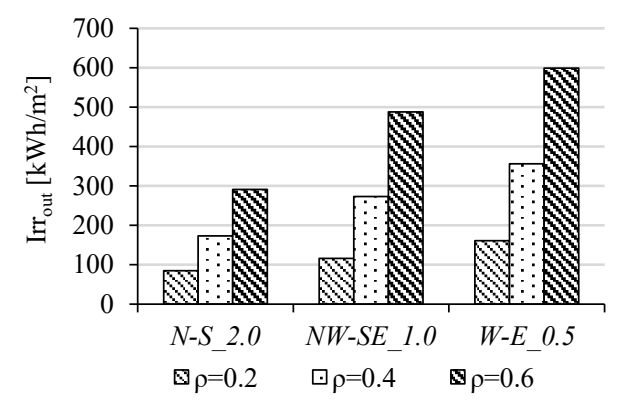

Figure 7: Outcomes from the solar analyses conducted on three representative geometry configurations varying the homogenous $\rho$ value of all the canyon's elements.

\section{Impact of cool materials on the best-configuration}

The scenario with traditional diffuse materials applied to the street and to the façade of the W-E_ 0.5 model shows an amount of annual $\operatorname{Irr}_{\text {out }}$ equal to $200 \mathrm{kWh} / \mathrm{m}^{2}$ (Figure 8 ). The seasonal contributions amount to $85 \mathrm{kWh} / \mathrm{m}^{2}$ and $20 \mathrm{kWh} / \mathrm{m}^{2}$ in summer and in winter, respectively.

When HR are considered as street's surface treatment, the irradiation reflected out of the UC is increased by more than $240 \%\left(690 \mathrm{kWh} / \mathrm{m}^{2}\right)$, while the seasonal $\Delta \mathrm{Irr}_{\%}$ is more than $280 \%$ in summer and around $160 \%$ in winter (Figure 8). The exploitation of HR on building's façade (HR-F) causes a lower variation in the estimated Irr $_{\text {out }}$, that achieves $320 \mathrm{kWh} / \mathrm{m}^{2}$ ( $\Delta \mathrm{Irr}_{\%}$ of $55 \%$ ). The seasonal amounts of solar energy leaving the canyon are 120 $\mathrm{kWh} / \mathrm{m}^{2}$ for the summer and $35 \mathrm{kWh} / \mathrm{m}^{2}$ for the winter (Figure 8).

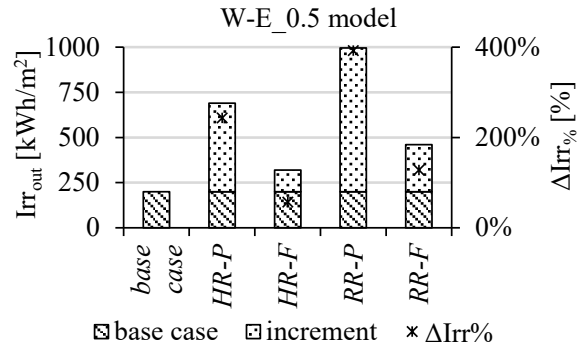

Figure 8: Amount of solar irradiation leaving the UC and percentage variation from the base case estimated for each material pattern of the best configuration.

Applying RR materials instead of HR allows reducing the amount of solar irradiation that remains trapped within the UC by improving the $\operatorname{Irr}_{\text {out }}$. The model with the RR street (RR-P) presents the greatest Irr $_{\text {out }}$. The yearly, summer, and winter values equal to $995 \mathrm{kWh} / \mathrm{m}^{2}, 475 \mathrm{kWh} / \mathrm{m}^{2}$, and $70 \mathrm{kWh} / \mathrm{m}^{2}$, while the $\Delta$ Irr\% ranges from $390 \%$ to $455 \%$, and to $255 \%$ (Figure 8 ). As far as the scenario with the $\mathrm{RR}$ façade (RR-F) is concerned, the UC reflects towards the sky dome $460 \mathrm{kWh} / \mathrm{m}^{2}$ per year $\left(\Delta \mathrm{Irr}_{\%}\right.$ of $\left.130 \%\right)$, while the $\operatorname{Irr}_{\text {out }}$ equals $140 \mathrm{kWh} / \mathrm{m}^{2}$ in summer and 75 $\mathrm{kWh} / \mathrm{m}^{2}$ in winter (Figure 8).

\section{Impact of cool materials on the worst-configuration}

When traditional materials are applied to the N-S 2.0 canyon model, the yearly amount of solar irradiation reflected beyond the $\mathrm{UC}$ is $150 \mathrm{kWh} / \mathrm{m}^{2}$ (Figure 9). The summer and winter seasons contribute for $65 \mathrm{kWh} / \mathrm{m}^{2}$ and $15 \mathrm{kWh} / \mathrm{m}^{2}$, respectively.

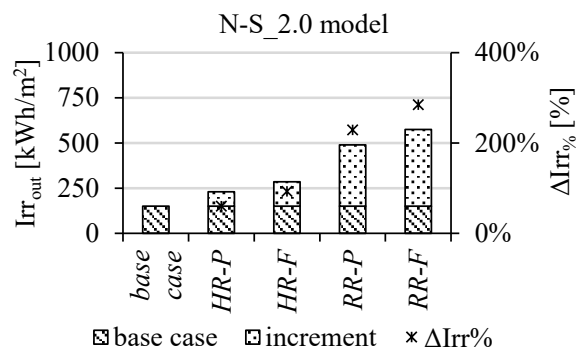

Figure 9: Amount of solar irradiation leaving the UC and percentage variation from the base case estimated for each material pattern of the worst configuration.

Enhancing the solar reflectance of the street through HR materials (HR-P) increases the $\operatorname{Irr}_{\text {out }}$ up to $240 \mathrm{kWh} / \mathrm{m}^{2}-$ $100 \mathrm{kWh} / \mathrm{m}^{2}$ in summer and $25 \mathrm{kWh} / \mathrm{m}^{2}$ in winter $(\Delta \mathrm{Irr} \%$ constantly equals $60 \%$ ). Conversely, the HR layer applied to the façade is able to increment the $\operatorname{Irr}_{\text {out }}$ by more than $90 \%$ annually $\left(285 \mathrm{kWh} / \mathrm{m}^{2}\right)$, while the seasonal contributions amount to $120 \mathrm{kWh} / \mathrm{m}^{2}$ in the summer and $30 \mathrm{kWh} / \mathrm{m}^{2}$ in the winter.

The scenario with RR applied to the street (RR-P) shows $490 \mathrm{kWh} / \mathrm{m}^{2}$ per year of specific solar irradiation leaving the UC ( $\Delta \mathrm{Irr}_{\%}$ of $\left.225 \%\right)$. The seasonal amounts are 210 $\mathrm{kWh} / \mathrm{m}^{2}$ in summer $\left(\Delta \mathrm{Irr}_{\%}\right.$ of around $230 \%$ ) and 50 $\mathrm{kWh} / \mathrm{m}^{2}$ in winter $\left(\Delta \mathrm{Irr}_{\%}\right.$ of $\left.220 \%\right)$. In the case study with the RR façade (RR-F), the greatest amounts of $\operatorname{Irr}_{\text {out }}$ for the N-S_2.0 model is observed: the annual $\operatorname{Irr}_{\text {out }}$ equals $575 \mathrm{kWh} / \mathrm{m}^{2}(\Delta \mathrm{Irr} \%$ is $285 \%)$, and it ranges from 
$275 \mathrm{kWh} / \mathrm{m}^{2}$ to $60 \mathrm{kWh} / \mathrm{m}^{2}$, in summer and winter, respectively ( $\Delta \mathrm{Irr}_{\%}$ varies from $330 \%$ to $310 \%$ ).

\section{Discussion}

\section{Potentials for the street application of RR materials}

The yearly solar analyses conducted in Milan demonstrate that applying RR to the street instead of HR is always advantageous to lower the solar energy trapped within the UC. Indeed, the RR coating significantly reduces the shortwave radiative exchanges among the street and the two façades by reflecting the solar irradiation incident on the street towards the sky dome. The efficiency of the RR technology strongly depends on the amount of specific solar irradiation impinging the treated surface: when applied to wide canyon environments, they usually perform better than when exploited in narrow configurations characterized by a shadowed street surface (Figure 8 and Figure 9). The same behaviour can be observed in HR surface treatments.

When it comes to the seasonal assessment of the RR materials' efficiency in N-S 2.0 model, it can be observed how the $\Delta \operatorname{Irr}_{\%}$ in summer is almost the same as in winter. Conversely, in the W-E_0.5, it is greater in the warm than in the cold season (Figure 10). Furthermore, the $\operatorname{Irr}_{\text {out }}$ values for winter are negatively affected by RR materials (and HR as well) which are responsible for the reduction of solar energy gains in buildings and the consequent raising of the heating energy demand.

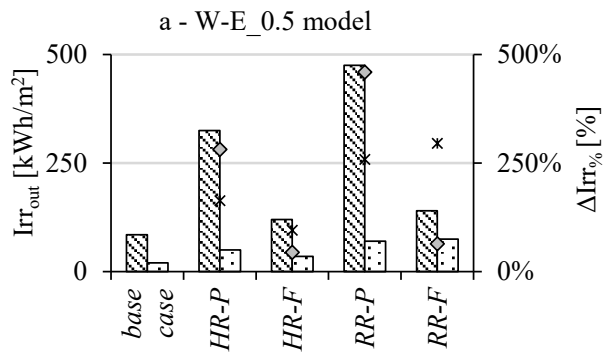

\$ summer $\Xi$ winter $\diamond \Delta \operatorname{Irr} \%$,summer $* \Delta \operatorname{Irr} \%$,winter

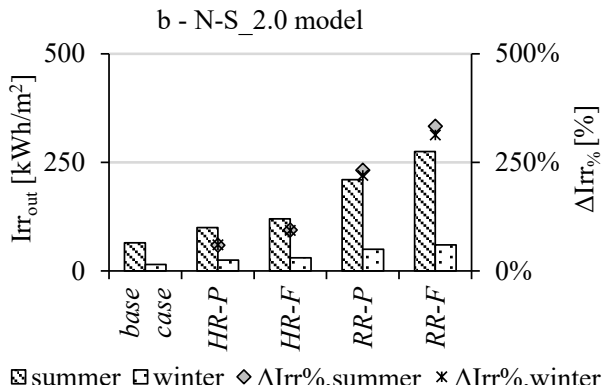

Figure 10: Amount of seasonal values of Irr out and $\Delta$ Irr\% estimated for each material pattern of the (a) best-and the (b) worst configuration.

The following practical guidelines about the application of RR layer to the street surface have been carried out from the results:

- Exploiting RR materials in wide UCs (low H/W) is more advantageous than in narrow ones (high $\mathrm{H} / \mathrm{W}$ ) where the street is shadowed for most of the time;
- RR materials applied to the street are more effective than HR during summer when they completely reflect the incident solar irradiation out of the $\mathrm{UC}$;

- In winter, the RR materials are responsible for the low solar energy gains within the UC.

\section{Potentials for façade application of RR materials}

The analyses conducted on the models enhanced with a RR façade defined the narrow canyon as the best façade application of RR materials. In the N-S 2.0 model, both the scenarios exploiting cool materials on the façade (HR$\mathrm{F}$ and RR-F) turn out to be more advantageous than the configurations with HR or RR paving. Indeed, the yearly $\Delta \mathrm{Irr} \%$ increases from $60 \%$ (HR-P) to more than $90 \%$ (HRF) and from $225 \%$ (RR-P) to $285 \%$ (RR-F) (Figure 8 and Figure 9).

The seasonal evaluation of the solar irradiation in $\mathrm{W}$ E 0.5 model shows RR materials increasing the $\operatorname{Irr}_{\text {out }}$ more in winter (when it is not necessary) than during summer (Figure 10). This trend is less evident in the HR configuration than in the RR, which can be considered, for this reason, as the worst among the investigated RR applications. When it comes to the N-S_2.0 model, the $\Delta \mathrm{Irr}_{\%}$ does not vary passing from the summer to the winter and it equals $315 \%$ (RR-F) (Figure 10). Similarly, the $\Delta \mathrm{Irr}_{\%}$ is constantly equal to $90 \%$ in the HR scenario.

The hereby practical guidelines about the exploitation of $\mathrm{RR}$ materials in the most irradiated façade summarize the outcomes from this study:

- RR materials applied to the façade are less performant in wide UCs (low H/W) than in narrow ones where façade surface is longer exposed to direct solar irradiation;

- RR materials are as advantageous as HR in terms of reduction of the solar energy trapped within wide UCs during summer;

- As demonstrated for the street application, RR materials are responsible for the reduction of winter's solar energy gains.

\section{Conclusions and future developments}

This study describes an approach for evaluating the impact of RR materials in relation to the increment of solar irradiation reflected out of the UC. The main findings can be summarized as follows:

- The UC configuration having traditional coatings on the surfaces with the greatest $\operatorname{Irr}_{\text {out }}$ value (200 $\mathrm{kWh} / \mathrm{m}^{2}$ ) is the W-E 0.5 model (main axis oriented eastwards and $\mathrm{H} / \mathrm{W}$ equal to 0.5 )

- The amount of solar direct irradiation impinging on the treated surface influences the performance of the RR materials;

- The façade application of the RR technology should be considered only for narrow canyons;

- RR materials applied to the street always perform better than HR during summer;

- All the investigated configurations can increase the Irr $_{\text {out }}$ during summer while reducing solar gains during winter. 
The outcomes highlighted how the investigated RR materials cannot be considered advantageous throughout the year when exploited in the building sector. Although they increase the Irr $_{\text {out }}$ more than HR in summer, they also contribute to reducing solar gains in winter. Thus, it is necessary to implement a selective behaviour - based on the angle of incidence of the sun rays - in the RR technology to activate its RR features only during the warm season.

The enhancement of the numerical model can represent an important step in the future developments of the present workflow allowing a better evaluation of the RR materials' performances and permitting handling parameters which cannot be fully replicated in the present modelling approach (i.e. angular dependency of the coating's reflectance value, directionality of the solar beam). Furthermore, its application to the assessment of angular-selective RR materials in different climatic contexts and scenarios would be fundamental as well.

\section{References}

Akbari, H. and Touchaei, A.G. (2014) Modeling and labeling heterogeneous directional reflective roofing materials. Solar Energy Materials and Solar Cells 124, 192-210.

Allegrini, J., Dorer, V. and Carmeliet, J. (2012) Influence of the urban microclimate in street canyons on the energy demand for space cooling and heating of buildings. Energy and Buildings 55, 823-832.

Han, Y., Taylor, J.E. and Pisello, A.L. (2015) Toward Mitigating Urban Heat Island Effects: Investigating the Thermal-Energy Impact of Bio-Inspired Retroreflective Building Envelopes in Dense Urban Settings. Energy and Buildings 102, 380-389.

Hassid, S., Santamouris, M., Papanikolaou, N., Linardi, A., Klitsikas, N., Georgakis, C., et al. (2000) Effect of the Athens heat island on air conditioning load. Energy and Buildings 32, 131-141.

Lima, I., Scalco, V. and Lamberts, R. (2019) Estimating the impact of urban densification on high-rise office building cooling loads in a hot and humid climate. Energy and Buildings 182, 30-44.

Manni, M., Lobaccaro, G., Goia, F. and Nicolini, A. (2018) An inverse approach to identify selective angular properties of retro-reflective materials for urban heat island mitigation. Solar Energy 176, 194-210.

Nilsen, R.B., \& Lu, X.J. (2004) Retroreflection technology. Proceedings from European Symposium on Optics and Photonics for Defence and Security. London (UK), 28 October 2004.

Pesenti, M., Masera, G. and Fiorito, F.F. (2018) Exploration of Adaptive Origami Shading Concepts through Integrated Dynamic Simulations. Journal of Architectural Engineering 24, 1-14.

Qin, Y., Liang, J., Tan, K. and Li, F. (2016) A side by side comparison of the cooling effect of building blocks with retro-reflective and diffuse-reflective walls. Solar Energy 133, 172-179.

Rossi, F., Castellani, B., Presciutti, A., Morini, E., Filipponi, M., Nicolini, A., et al. (2015) Retroreflective façades for urban heat island mitigation: Experimental investigation and energy evaluations. Applied Energy 145, 8-20.

Rossi, F., Pisello, A.L., Nicolini, A., Filipponi, M. and Palombo, M. (2014) Analysis of retro-reflective surfaces for urban heat island mitigation: A new analytical model. Applied Energy 114, 621-631.

Sakai, H., Emura, K. and Igawa, N. (2008) Reduction of reflected heat by retroreflective materilas. Journal of Structural and Construction Engineering 73, 1239-1244.

Sakai, H. and Iyota, H. (2017) Development of Two New Types of Retroreflective Materials as Countermeasures to Urban Heat Islands. International Journal of Thermophysics 38, 131141.

Santamouris, M. (2014) On the energy impact of urban heat island and global warming on buildings. Energy and Buildings 82, 100-113.

Santamouris, M., Cartalis, C., Synnefa, A. and Kolokotsa, D. (2015) On the impact of urban heat island and global warming on the power demand and electricity consumption of buildings - A review. Energy and Buildings 98, 119-124.

Santamouris, M. and Kolokotsa, D. (2015) On the impact of urban overheating and extreme climatic conditions on housing, energy, comfort and environmental quality of vulnerable population in Europe. Energy and Buildings 98, 125-133.

Santamouris, M., Paraponiaris, K. and Mihalakakou, G. (2007) Estimating the ecological footprint of the heat island effect over Athens, Greece. Climatic Change 80, 265-276.

Stathopoulou, E., Mihalakakou, G., Santamouris, M. and Bagiorgas, H.S. (2008) On the impact of temperature on tropospheric ozone concentration levels in urban environments. Journal of Earth System Science 117, 227-236.

Vallati, A., Mauri, L. and Colucci, C. (2018) Impact of shortwave multiple reflections in an urban street canyon on building thermal energy demands. Energy and Buildings 174, 77-84.

Xu, X., González, J.E., Shen, S., Miao, S. and Dou, J. (2018) Impacts of urbanization and air pollution on building energy demands - Beijing case study. Applied Energy 225, 98-109.

Yuan, J., Emura, K. and Farnham, C. (2016) Potential for Application of Retroreflective Materials instead of Highly Reflective Materials for Urban Heat Island Mitigation. Urban Studies Research 5, 1-10. 